\title{
Terminally differentiated astrocytes lack DNA damage response signaling and are radioresistant but retain DNA repair proficiency
}

\author{
L Schneider ${ }^{\star, 1}$, M Fumagalli ${ }^{1}$ and $F$ d'Adda di Fagagna ${ }^{*, 1}$
}

The impact and consequences of damage generation into genomic DNA, especially in the form of DNA double-strand breaks, and of the DNA-damage response (DDR) pathways that are promptly activated, have been elucidated in great detail. Most of this research, however, has been performed on proliferating, often cancerous, cell lines. In a mammalian body, the majority of cells are terminally differentiated (TD), and derives from a small pool of self-renewing somatic stem cells. Here, we comparatively studied DDR signaling and radiosensitivity in neural stem cells (NSC) and their TD-descendants, astrocytes - the predominant cells in the mammalian brain. Astrocytes have important roles in brain physiology, development and plasticity. We discovered that NSC activate canonical DDR upon exposure to ionizing radiation. Strikingly, astrocytes proved radioresistant, lacked functional DDR signaling, with key DDR genes such as ATM being repressed at the transcriptional level. Nevertheless, astrocytes retain the expression of non-homologous end-joining (NHEJ) genes and indeed they are DNA repair proficient. Unlike in NSC, in astrocytes DNA-PK seems to be the PI3K-like protein kinase responsible for $\gamma \mathrm{H} 2 \mathrm{AX}$ signal generation upon DNA damage. We also demonstrate the lack of functional DDR signaling activation in vivo in astrocytes of irradiated adult mouse brains, although adjacent neurons activate the DDR.

Cell Death and Differentiation (2012) 19, 582-591; doi:10.1038/cdd.2011.129; published online 7 October 2011

Damage to genomic DNA elicits swift activation of DNAdamage response (DDR), a molecular signaling cascade, which coordinates DNA repair, cell cycle arrest, and ultimately apoptosis or cellular senescence. ${ }^{1,2}$ Presently, most of DDR research is performed on proliferating and often transformed cells or, occasionally, transiently arrested quiescent cells. Yet the overwhelming majority of cells in multicellular organisms is terminally differentiated (TD) and does not proliferate. Nondividing TD cells of the soma derive from proliferating or proliferation-proficient somatic stem and progenitor cells. However, it is unclear whether, and to which extent, somatic stem cells and their TD descendants respond to DNA damage by engaging the canonical DDR pathways observed in most commonly experimentally used cell systems. Likewise, the radiosensitivity of these two distinct cell types is poorly characterized.

The canonical DDR pathways are now well elucidated., ${ }^{1,2}$ DNA double-strand breaks (DSBs) generation triggers the autophosphorylation and consequent activation of the apical PI3K-like protein kinase ATM at serine 1981 (S1981), which is detectable in the form of nuclear foci assembling at DSB sites. ${ }^{3}$ Upon activation, ATM labels chromatin break sites over large distances of the chromosome through serine139 (S139) phosphorylation of the histone $\mathrm{H} 2 \mathrm{~A}$ variant $\mathrm{H} 2 \mathrm{AX}(\gamma \mathrm{H} 2 \mathrm{AX}) .{ }^{4}$ The serine/threonine kinase ATM targets a large number of downstream effectors with various enzymatic and transcriptional regulation capacities by phosphorylating their evolutionarily conserved serine/threonine-glutamine (S/TQ) target motif. ${ }^{1}$ Some of these effectors, such as 53BP1 are focally recruited by ATM to DSB. ${ }^{5,6}$ Protein kinases like CHK2 and transcription factors like p53 further relay DDR signaling throughout the nucleus ultimately regulating cell cycle progression and survival. ${ }^{1,2}$

DSB can be repaired by two major mechanisms. Homologous recombination operates mainly in $S-G_{2}$ phases, ${ }^{7}$ therefore it is not active in $\mathrm{G}_{0}$-arrested and TD cells. In these cells, DSB repair relies mainly on non-homologous endjoining (NHEJ). ${ }^{7}$ This pathway depends on the activity of a PI3K-like DNA-dependent protein kinase (DNA-PK), which consists of DNA-PK catalytic subunit (DNA-PKcs), KU70 and KU80 subunits of the KU heterodimer, and on the activity of DNA ligase 4 and its associated cofactor XRCC4. ${ }^{8}$ Similarly to ATM, DNA-PK preferentially recognizes and phosphorylates a $S / T Q$ motif. $^{8}$

In this study, we addressed DDR signaling and radioresistance of TD astrocytes, which are the predominant cell type in the mammalian brain and have key roles in brain physiology, development and plasticity. ${ }^{9}$ Glial cells like astrocytes, but also neurons, derive from neural stem cells (NSC) residing in specific brain areas. ${ }^{10}$ It is known from previous studies that ionizing radiation received prenatally from atom bomb explosions in Japan had debilitating effects

${ }^{1}$ IFOM Foundation - The FIRC Institute of Molecular Oncology Foundation, Via Adamello 16, 20139 Milan, Italy

*Corresponding author: F d'Adda di Fagagna or L Schneider, IFOM Foundation - The FIRC Institute of Molecular Oncology Foundation, Via Adamello 16, 20139 Milan, Italy. Tel: + 3902574303 227; Fax: + 3902574303 231; E-mail: fabrizio.dadda@ @ifom-ieo-campus.it or leonid.schneider@ifom-ieo-campus.it

Keywords: DNA-damage response; astrocytes; neural stem cells

Abbreviations: ATMi, ATM inhibitor; DDR, DNA-damage response; DPKi, DNA-PK inhibitor; DSB, DNA double strand break; FCS, fetal calf serum; NHEJ, nonhomologous end-joining; NSC, neural stem cells; TD, terminally differentiated

Received 03.6.11; revised 06.8.11; accepted 22.8.11; Edited by D Kaplan; published online 07.10.11 
on human brain development ${ }^{11}$ and the risk of mental retardation is a crucial safety issue for radiation therapy during pregnancy. ${ }^{12}$ We find it necessary to combine today's knowledge of stem cells, differentiation and molecular DDR signaling to better understand the impact of DNA-damage generation in the brain. In our study, we interrogate murine NSC and their TD descendants astrocytes by comparatively testing the functionality of their DDR pathways at the molecular level in vitro and in vivo.

\section{Results}

In order to comparatively assess DDR signaling in somatic stem cells and their TD descendants, we employed murine ES-cell-derived NSC, which are fully tri-potent in their ability to differentiate into neurons, oligodendrocytes and astrocytes. ${ }^{13}$ We employed the established method of rapid and efficient differentiation of NSC into astrocytes by supplementing the growth medium with fetal calf serum (FCS). ${ }^{13}$ FCS induces a proliferative arrest associated with morphological changes typical of astrocytic differentiation in all cultured cells within 24-48 h (Supplementary Figure S1 and data not shown); in order to assure a complete terminal differentiation, all experiments were performed 7 days following FCS treatment.

First, we aimed to determine whether NSC and NSCderived astrocytes exposed to X-rays are capable of responding to genotoxic insults by the activation of a robust canonical DDR. For this purpose, we studied the formation of nuclear foci of the activated key components of the DDR signaling cascade by means of immunofluorescence analysis and confocal microscopy. In order to ascertain the differential cell types studied, we took advantage of the fact that NSC are virtually negative for the intermediate filament glial fibrillary acidic protein (GFAP), whereas TD-astrocytes express high levels of GFAP (Figure 1). ${ }^{13}$ As readout for DDR activation, we stained NSC and astrocytes for the autophosphorylated and thus activated form of ATM (ATMpS1981), for phosphorylated S/TQ epitope (pS/TQ), 53BP1 and $\gamma \mathrm{H} 2 \mathrm{AX}$ foci $1 \mathrm{~h}$ after exposure of cells to X-rays (10 Gy). We observed that NSC show bright nuclear foci for all the four markers analyzed, whereas non-irradiated cells showed virtually no nuclear foci assembly (Figure 1a and Supplementary Figure S2). Astrocytes, however, when processed in parallel, show a comparably strongly reduced phospho-ATM foci formation and no detectable $\mathrm{pS} / \mathrm{TQ}$ or 53BP1 nuclear foci $1 \mathrm{~h}$ after irradiation. Even a large dose of $50 \mathrm{~Gy}$ fails to elicit 53BP1 foci formation in astrocytes (Supplementary Figure S3). Remarkably though, $\gamma \mathrm{H} 2 \mathrm{AX}$ is still clearly detectable in astrocytes, indicating the presence of irradiation-induced $\mathrm{S}$ / TQ kinase activity (Figure $1 \mathrm{~b}$ and Supplementary Figure S2). In order to ascertain the colocalisation of $\gamma \mathrm{H} 2 \mathrm{AX}$ foci with other DDR markers, such as 53BP1, we irradiated NSC and astrocytes with $1 \mathrm{~Gy}$ only (Supplementary Figure S3). Due to fewer DSBs generated, discrete and separate $\gamma \mathrm{H} 2 \mathrm{AX}$ foci can be clearly detected in NSC and astrocytes and, in the former, $\gamma \mathrm{H} 2 \mathrm{AX}$ and 53BP1 foci neatly colocalize.

Next we investigated whether the suppressed DDR signaling in astrocytes might be the consequence of altered expression pattern of DDR gene associated with astrocytic differentiation.
We comparatively quantified the mRNA expression levels of DDR factors ATM, MRE11, MDC1, CHK2 and p53 by quantitative RT-PCR (qRT-PCR) in TD-astrocytes versus NSC. We found all these genes to be transcriptionally strongly downregulated in astrocytes when considering their individual expression levels in NSC as reference (Figure 2a). Although DDR signaling was suppressed, our qRT-PCR analysis, however, revealed that the NHEJ pathway of DNA repair was not significantly downregulated (Figure 2a), as shown for DNA-PKCS, KU70, KU80, ligase 4 (LIG4), XRCC4 and 53BP1 gene expression levels - the latter was recently reported to be involved also in DNA repair. ${ }^{14}$

We then comparatively studied the ATM-dependent DDR signaling in irradiated NSC and astrocytes by the means of western blot analyses. In NSC, irradiation lead to ATM autophosphorylation and a mobility shift of $\mathrm{CHK} 2$, suggesting its DNA-damage-induced phosphorylation, whereas in astrocytes phospho-ATM was not detectable at 1 or $24 \mathrm{~h}$ after irradiation and $\mathrm{CHK} 2$ protein was completely absent (Figure $2 b$ ), in agreement with their gene expression profiles (Figure 2a). Reflecting the insufficient ATM signaling in astrocytes, 53BP1 was not recruited or retained at the DNAdamage sites (Figure 1b), despite being expressed in astrocytes at levels comparable to NSC (Figures $2 a$ and $b$ ).

We also determined that DNA-damage-induced phosphorylation of p53 at serine-15 (S15, a residue targeted by ATM) and accumulation of p53 protein, ${ }^{15}$ were fully functional in NSC, although less pronounced in irradiated astrocytes (Figure 2b, left panel). Still, we could detect some transcriptional upregulation of the p53 transcriptional gene target p21 ${ }^{\mathrm{CIP}}$ (Figure 2c). As we failed to detect the p21 ${ }^{\mathrm{ClP}}$ protein by western blotting in irradiated astrocytes, as opposed to irradiated NSC (Supplementary Figure S4A), this upregulation of p21 CIP mRNA is likely insufficient to achieve a significant physiological impact. Another cell cycle controlling p53-target, GADD45 $\alpha$, was found unchanged, and the pro-apoptotic p53-target genes $B A X$ and $P U M A^{16}$ were induced only very weakly (Figure $2 \mathrm{c}$ ). In irradiated NSC, however, we detected a robust upregulation of PUMA transcript (Supplementary Figure S4B). We also tested whether DDR genes transcriptional suppression in astrocytes can be reversed by a challenge with DNA damage and performed a qRT-PCR analysis for the same DDR factors studied in Figure 2a on irradiated astrocytes (24 h after $10 \mathrm{~Gy}$ exposure) versus unchallenged astrocytes. Remarkably, we saw no change in the DDR gene expression (Figure 2c).

In order to test whether these findings are also applicable to adult NSC and their astrocyte descendants, we employed NSC derived from adult murine forebrain. ${ }^{13}$ We derived astrocytes from these cells and performed comparative analyse of DDR in adult NSC and astrocytes (Supplementary Figure S5). Indeed, we could observe that, upon irradiation, GFAP-expressing astrocytes have strongly attenuated phosphorylation and reduced protein levels of ATM, CHK2 and p53 when compared with parental adult NSC (Supplementary Figure S5A). Also in this setup, we found these and other DDR factors to be transcriptionally downregulated upon astrocytic differentiation (Supplementary Figure S5B).

Although we did not detect any functional activation of key DDR proteins in astrocytes, even after 50 Gy of irradiation, 
a
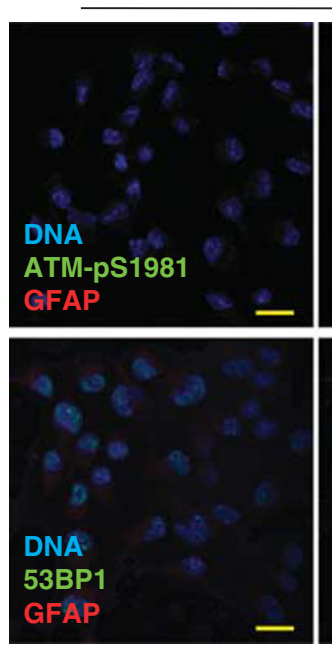

b
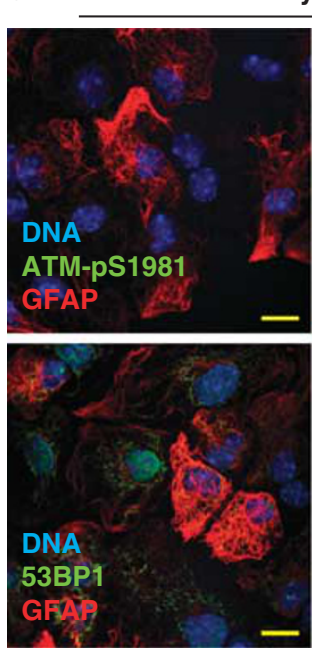

NSC ctrl
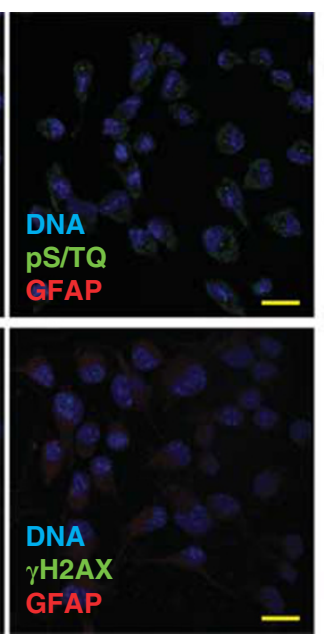

Astrocytes ctrl
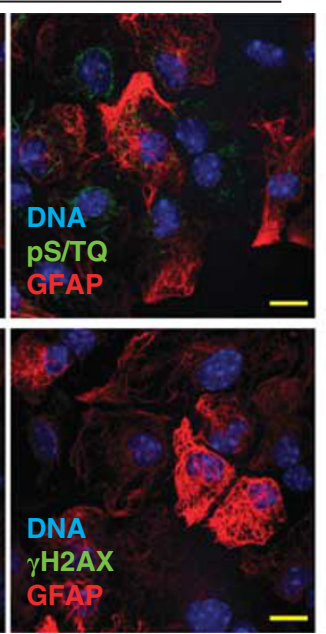

NSC 10Gy $1 \mathrm{~h}$
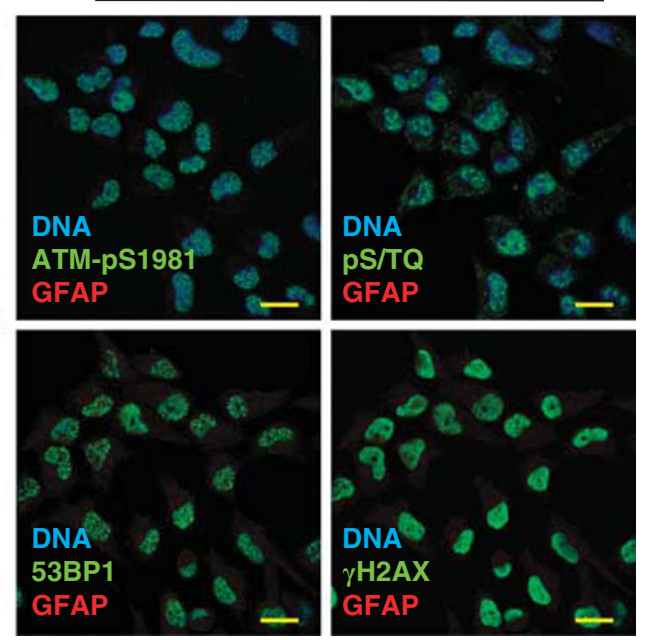

Astrocytes 10Gy 1h
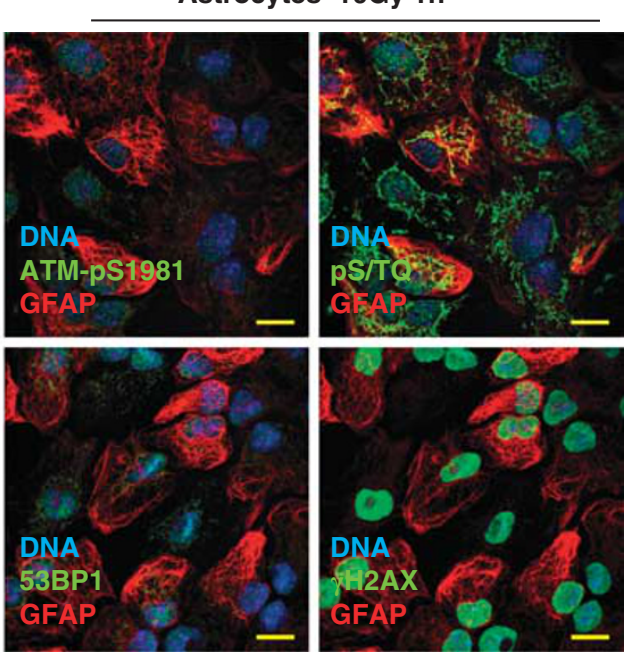

Figure 1 NSC show efficient DDR activation whereas this is strongly impaired in NSC-derived astrocytes. (a) At $1 \mathrm{~h}$ after irradiation with 10 Gy, NSC (here, negative for intermediate filament GFAP) uniformly display ATM kinase activity as demonstrated by the detection of foci of autophosphorylated ATM (S1981), ATM/ATR/DNA-PK-specific phospho-epitopes (pS/TQ), 53BP1 and of the phosphorylated histone $\mathrm{H} 2 \mathrm{AX}(\gamma \mathrm{H} 2 \mathrm{AX})$, as analyzed by confocal microscopy of immunofluorescence stainings. Bar: $15 \mu \mathrm{m}$. (b) In contrast, astrocytes (positive for intermediate filament GFAP) when irradiated and treated in parallel with NSC, show only marginal phospho-ATM foci appearance and nearly no nuclear signal of 53BP1 or pS/TQ foci. However, astrocytes still display irradiation-induced nuclear $\gamma \mathrm{H} 2 \mathrm{AX}$ signal. Bar: $15 \mu \mathrm{m}$

when we performed a detailed kinetics analysis of ATM phosphorylation in irradiated astrocytes, we could detect its delayed and transient appearance by western blotting (Figure 3a), implying a potential function for the observed residual activated ATM.

Interestingly, $3 \mathrm{~h}$ after irradiation the intensity of $\gamma \mathrm{H} 2 \mathrm{AX}$ signal already started to diminish and $24 \mathrm{~h}$ after irradiation $\gamma \mathrm{H} 2 \mathrm{AX}$ was barely detectable in astrocytes (Figure 3a). $\gamma \mathrm{H} 2 \mathrm{AX}$ signal is generally considered a reliable marker of DSB presence. ${ }^{17}$ To test whether its downregulation is the outcome of DNA-damage repair or attenuation of $\mathrm{H} 2 \mathrm{AX}$ phosphorylation in these cells, we re-irradiated astrocytes $24 \mathrm{~h}$ after the first round of irradiation. Here, the already extinguished initial $\gamma \mathrm{H} 2 \mathrm{AX}$ signal could be fully detected again $1 \mathrm{~h}$ after the second round of irradiation (Figures $3 \mathrm{c}$ and $\mathrm{d}$ ), indicating that loss of $\gamma \mathrm{H} 2 \mathrm{AX}$ signal in astrocytes $24 \mathrm{~h}$ after irradiation is not caused by an irradiation-induced decline in H2AX phosphorylation proficiency.

Noteworthy, even combined irradiation of 20 Gy was unable to induce a significant increase in apoptosis as compared with non-irradiated astrocytes (Figure 3b). In NSC, already a single irradiation of $10 \mathrm{~Gy}$ lead to distinct apoptosis when measured $72 \mathrm{~h}$ later (Figure 3b), demonstrating, consistently with their lack of robust DDR signaling, that astrocytes are radioresistant as compared with parental NSC.

ATM is the main kinase involved in $\gamma \mathrm{H} 2 \mathrm{AX}$ generation upon DSB formation. ${ }^{4,5}$ Yet, also the other two DNA-dependent PI3K-like protein kinases, ATR and DNA-PK, are capable of phosphorylating $\mathrm{H} 2 \mathrm{AX} .{ }^{17}$ Our data, however, provide little evidence that ATR may have any functional role in astrocytes, as we could not detect ATR protein by western blotting, consistently with ATR's nature as S-phase-specific PI3K-like 
a

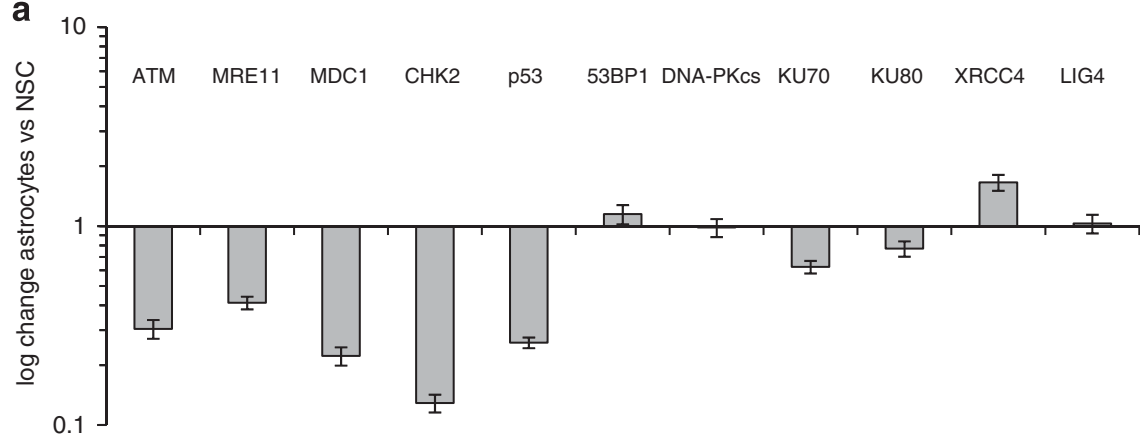

b
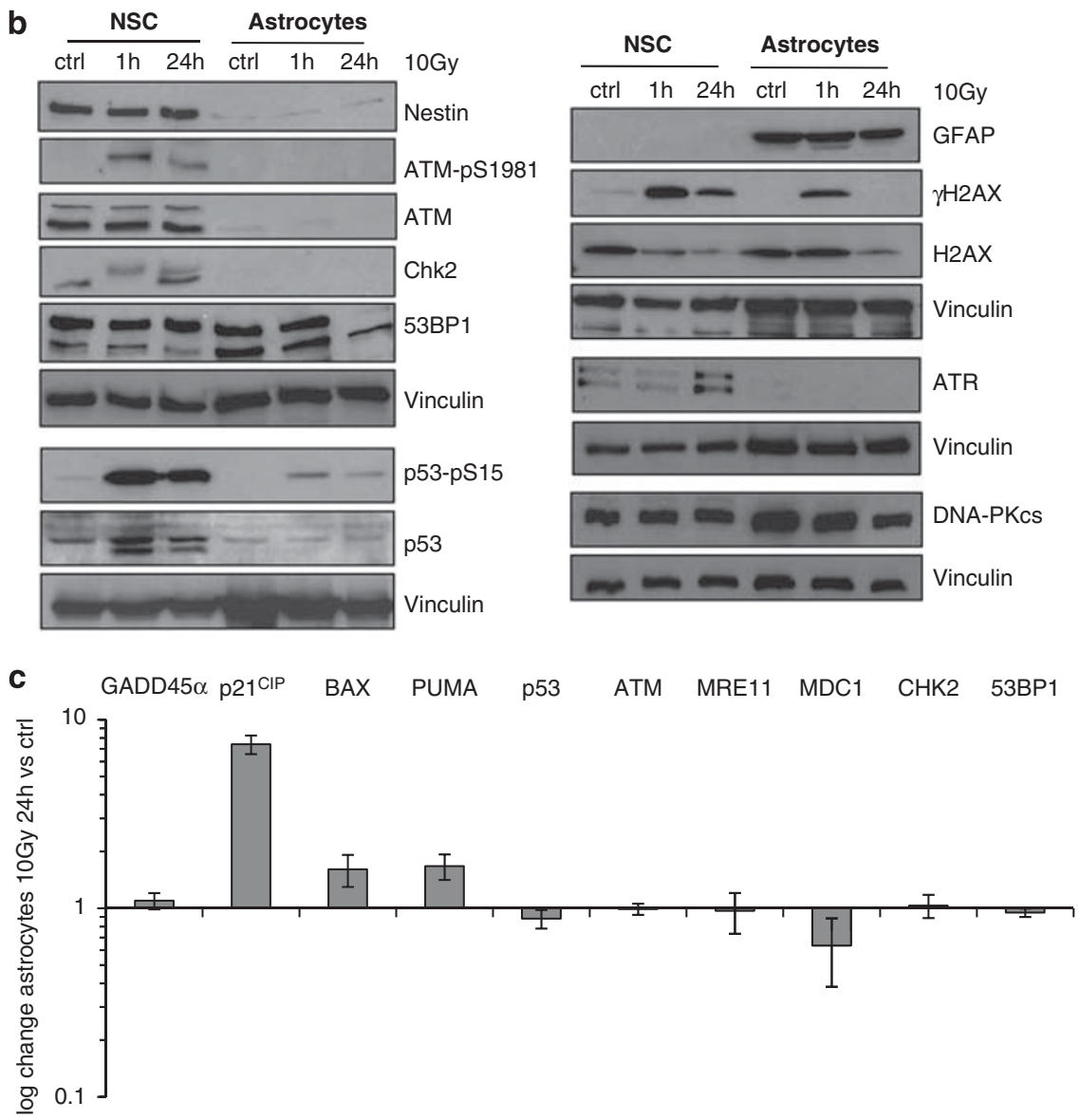

Figure 2 DDR response factors are transcriptionally suppressed in astrocytes, whereas NSC show canonical DDR upon irradiation. (a) Quantitative RT-PCR analysis reveals a transcriptional downregulation of DDR genes, but retained expression of DNA repair factors, in astrocytes. Expression profiles were normalized against parental NSC before serum-induced differentiation. 32 -microglobulin was used as a housekeeping gene. (b) Western blot analysis of NSC and astrocytes, irradiated and processed in parallel. Membranes were probed with phospho-specific and total antibodies as shown and normalized for vinculin. (c) Quantitative RT-PCR analysis showing that even $24 \mathrm{~h}$ following irradiation, key DDR factors remain downregulated in astrocytes. Four target genes of p53 were also analyzed: transcripts of GADD45a, BAX and PUMA remained largely unchanged. The mRNA of the cell-cycle control gene p21 ${ }^{\mathrm{ClP}}$ was found upregulated. Expression profiles were normalized against non-irradiated astrocytes. $\beta 2$-microglobulin was used as a housekeeping gene

protein kinase. ${ }^{17}$ Differently, DNA-PKcs was expressed in astrocytes at levels comparable to NSC (Figure 2). Based on these observations, we set on to elucidate the roles of ATM and DNA-PK in the DNA-damage-induced H2AX phosphorylation in NSC and astrocytes using following small molecule inhibitors: a DNA-PK inhibitor ${ }^{18}$ (DPKi, NU7441) and an ATM inhibitor $^{19}$ (ATMi, KU55933) or both inhibitors in combination. Under these conditions, we analyzed the intensity of $\gamma \mathrm{H} 2 \mathrm{AX}$ signal by two different methods: western blotting of total cell extracts (Figure 4a) and flow cytometrical immunofluorescence analysis at the single cell level (Figure $4 \mathrm{~b}$ and Supplementary Figure S7). In NSC, inhibition of ATM had a profound impact on DNA-damage-induced phosphorylation of not only ATM-S1981, but also $\gamma \mathrm{H} 2 \mathrm{AX}$ as well as on the overall S/TQ phosphorylation pattern, whereas the inhibition of DNAPK in NSC had no appreciable effect on any of these 


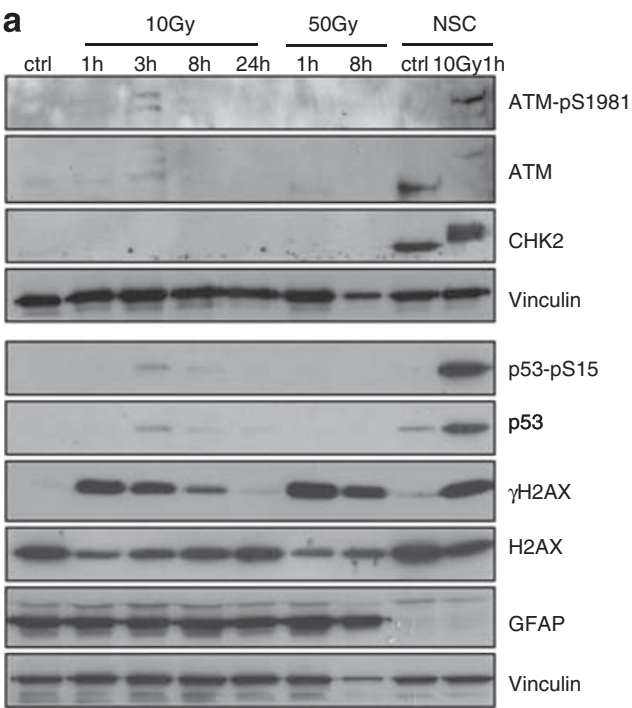

b

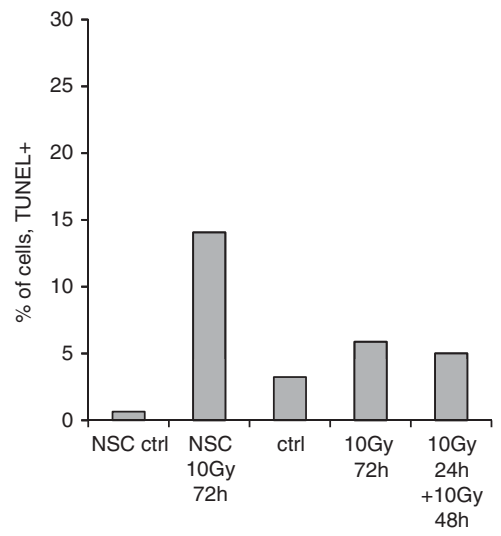

C

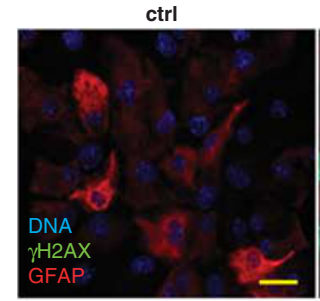

10Gy 24h

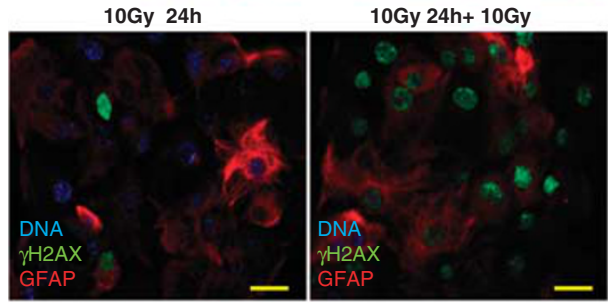

10Gy $1 \mathrm{~h}$

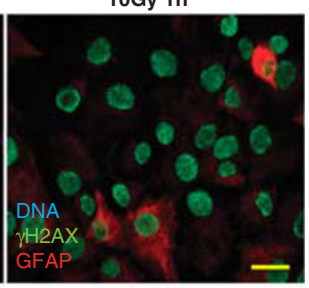

$10 G y 24 h+10 G y$ d

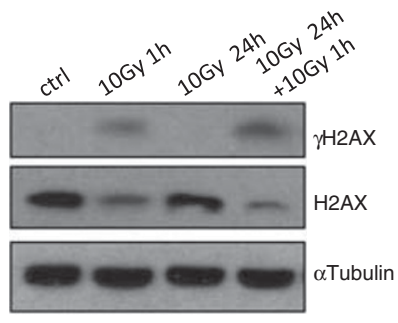

Figure 3 Residual ATM activity can be detected in irradiated astrocytes and parallels the downregulation of the $\gamma H 2 A X$ signal. (a) Western blot analysis of DDR kinetics in astrocytes, irradiated with $10 \mathrm{~Gy}$. Weak and transient phospho-ATM signal can be detected and coincides with reduction of $\gamma \mathrm{H} 2 \mathrm{AX}$ and increase in p53 signal. Note that even 50 Gy fail to induce any strong DDR in astrocytes. Irradiated NSC were used as positive control. Membranes were probed with phospho-specific and total antibodies and normalized for vinculin. (b) TUNEL assay for apoptosis-induced DSB in astrocytes $72 \mathrm{~h}$ after irradiation with 10 Gy. Note that also re-irradiation with further $10 \mathrm{~Gy} 24 \mathrm{~h}$ after the first exposure to X-rays fails to induce apoptosis. NSC $72 \mathrm{~h}$ after $10 \mathrm{~Gy}$ irradiation show a profound induction of apoptosis compared with non-irradiated NSC. (c) Immunofluorescence analysis showing the DNA-damage-induced appearance of $\gamma \mathrm{H} 2 \mathrm{AX}$ signal in irradiated astrocytes. After $24 \mathrm{~h}$, the foci are strongly downregulated, indicating repair. Another round of irradiation leads to a de novo formation of the $\gamma \mathrm{H} 2 \mathrm{AX}$ signal, indicating a still functional $\mathrm{H} 2 \mathrm{AX}$ phosphorylation machinery. Bar: $\sim 22 \mu \mathrm{m}$. (d) Similar observations can also be made by western blot analysis. Membrane was probed with phospho-specific and total antibody against $\mathrm{H} 2 \mathrm{AX}$ and normalized for $\alpha$-tubulin

parameters (Figure 4a and Supplementary Figure S6). Vice versa, in astrocytes, DPKi showed a strong inhibitory impact on H2AX phosphorylation, whereas ATMi did not have such an effect (Figure 4a). These findings were reproduced by flow cytometrical (Figure $4 \mathrm{~b}$ and Supplementary Figure S7) and immunofluorescence analyses (Figure $4 \mathrm{c}$ and Supplementary Figure S8), where DNA-PK, but not ATM inhibition in astrocytes $1 \mathrm{~h}$ after irradiation notably reduced the population of highly $\gamma \mathrm{H} 2 \mathrm{AX}$-positive cells and the intensity of the $\gamma \mathrm{H} 2 \mathrm{AX}$ signal, respectively.

We have shown ATM in astrocytes to be strongly reduced, but not to undetectable levels (Figure 3a). Next we set on to elucidate, why its pharmacological inhibition did not lead to any reduction of $\gamma \mathrm{H} 2 \mathrm{AX}$ levels. We performed a COMET assay $^{20}$ under neutral conditions, which allows to directly and quantitatively detect DNA DSB in individual cells (Figure 4c). In the COMET assay, gel electrophoresis revealed 'tails' generated by broken DNA in irradiated astrocytes, and for each individual cell a so-called Olive tail moment was calculated. As above, we treated cells before irradiation with DPKi, ATMi or both inhibitors in combination. At $1 \mathrm{~h}$ after irradiation, the median Olive tail moment of KU55933-treated cells was significantly higher than that of DMSO or DPKi alone treated cells, indicating higher number of DSB. After $24 \mathrm{~h}$, cells were able to repair DNA under all conditions (as indicated by the reduction of the Olive tail moment), but significantly less efficiently when treated with both inhibitors together. These findings indicate that, despite its low 
a

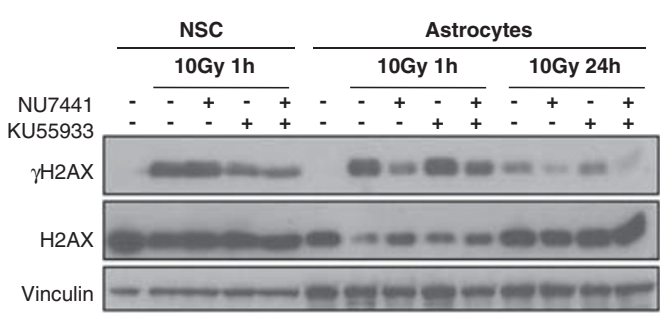

C
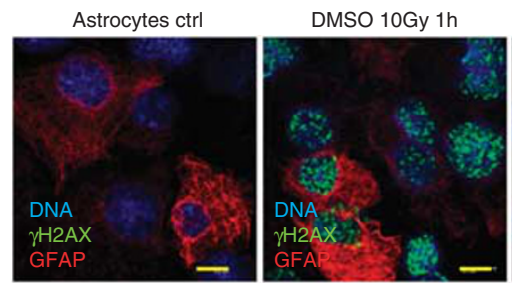

b

$\gamma \mathrm{H} 2 \mathrm{AX}$ signal intensity

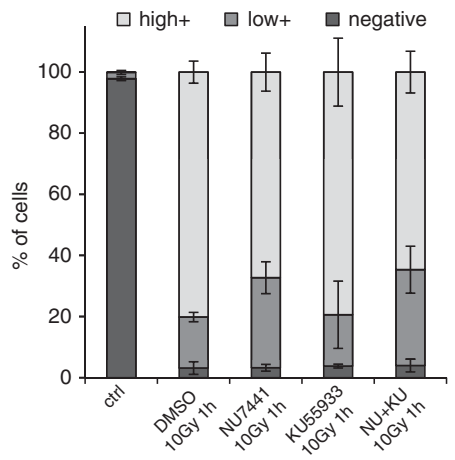

NU7441 10Gy 1h

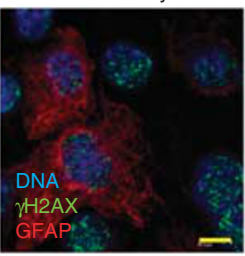

d

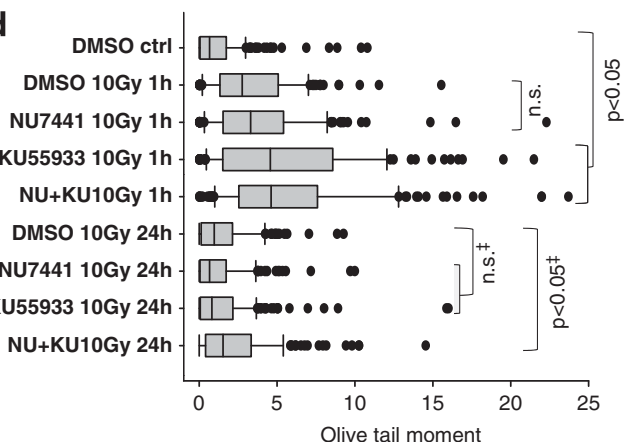

e

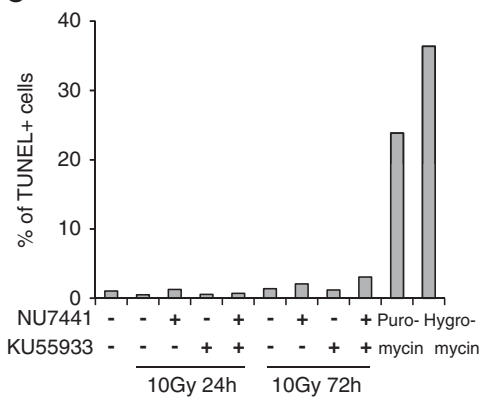

Figure 4 Astrocytes display functional ATM-biased DNA repair and DNA-PK-biased H2AX phosphorylation, but no apoptotic response upon irradiation. (a) Western blot analysis of NSC and astrocytes, treated with a solvent (DMSO) or DNA-PK inhibitor NU7441 and ATM inhibitor KU55933, separately or in combination (NU + KU) at concentrations of $1 \mu \mathrm{M}$ each (lower than IC50 values of the inhibitor's second most sensitive PI3K-like protein kinase target), irradiated and processed in parallel. The membrane was probed for the phosphorylated and total form of $\mathrm{H} 2 \mathrm{AX}$ and normalized with vinculin. (b) Flow cytometrical analysis of astrocytes, treated with inhibitors as above, irradiated and stained with antibody against $\gamma \mathrm{H} 2 \mathrm{AX}$. Alexa488 secondary antibody signal was measured on $\log _{10} \mathrm{scale}$. Gates were set to discriminate $\gamma \mathrm{H} 2 \mathrm{AX}$-negative cells, whereas $\gamma \mathrm{H} 2 \mathrm{AX}$ positive cells were arbitrarily subdivided into high and low positive. Same gateset was used for all measurements of each experiment done in quadruplicate. Error bars show S.D. (c) Confocal immunofluorescence analysis of astrocytes irradiated with $1 \mathrm{~Gy}$ to better discriminate $\gamma \mathrm{H} 2 \mathrm{AX}$ foci. Note the reduction of the $\gamma \mathrm{H} 2 \mathrm{AX}$ signal intensity in irradiated astrocytes, treated with DNA-PK inhibitor NU7441. Bar: $10 \mu \mathrm{m}$. (d) DSB detection by neutral COMET assay in astrocytes 1 and $24 \mathrm{~h}$ after irradiation, treated with inhibitors as above. Olive tail moments are presented as box plot diagram, with vertical bars indicating median values. Error bars show S.D. Significance of the median values was calculated with Dunn's method with DMSO-treated cells as control group. " same significance ratio applies when non-irradiated cells are used as reference. (e) TUNEL assay for apoptosis-induced DSB in astrocytes 24 and $72 \mathrm{~h}$ after irradiation, treated with inhibitors as above. As a positive control for apoptotic proficiency of astrocytes, cells were treated for 2 days with puromycin $(5 \mu \mathrm{g} / \mathrm{ml})$ or hygromycin $(800 \mu \mathrm{g} / \mathrm{ml})$

expression levels, ATM has a role in DNA repair in astrocytes and it acts in conjunction with DNA-PK. In combination with ATM inhibition, DPKi treatment lead to a significant retention of unrepaired DSB breaks in astrocytes even $24 \mathrm{~h}$ after irradiation (Figure 4c), indicating that ATM and DNA-PK are both involved in the DSB-repair in astrocytes.

Noteworthy, we again did not observe an apoptotic response in astrocytes 3 days after exposure to $10 \mathrm{~Gy}$ irradiation, with or without additional treatments with ATMi and DNA-PKi. However, as a control, non-genotoxic cell poisons puromycin and hygromycin $\mathrm{B}$ were able to elicit strong apoptotic response in NSC-derived astrocytes (Figure 4e).
NSC are also responsible for the generation of neurons. Hence, we decided to analyze the functionality of DDR signaling in NSC-derived neurons, as generated by the use of an established in vitro differentiation protocol. ${ }^{21}$ Neurons derived in this manner stop proliferating, express markers specific for TD- neurons (such as the cytoskeletal filament protein Tuj1, also known as $\beta$-tubulin-III) and can therefore be regarded as TD (Supplementary Figure S9A). ${ }^{13}$ We irradiated these neuron cultures with 10 Gy in parallel with parental NSC and analyzed them under the same conditions. Tuj1 was used as a specific marker in order to detect TD neurons by immunofluorescence and confocal microscopy (Figure 5a). In both cell types, no nuclear $\mathrm{pS} / \mathrm{TQ}$ signal was detectable in 

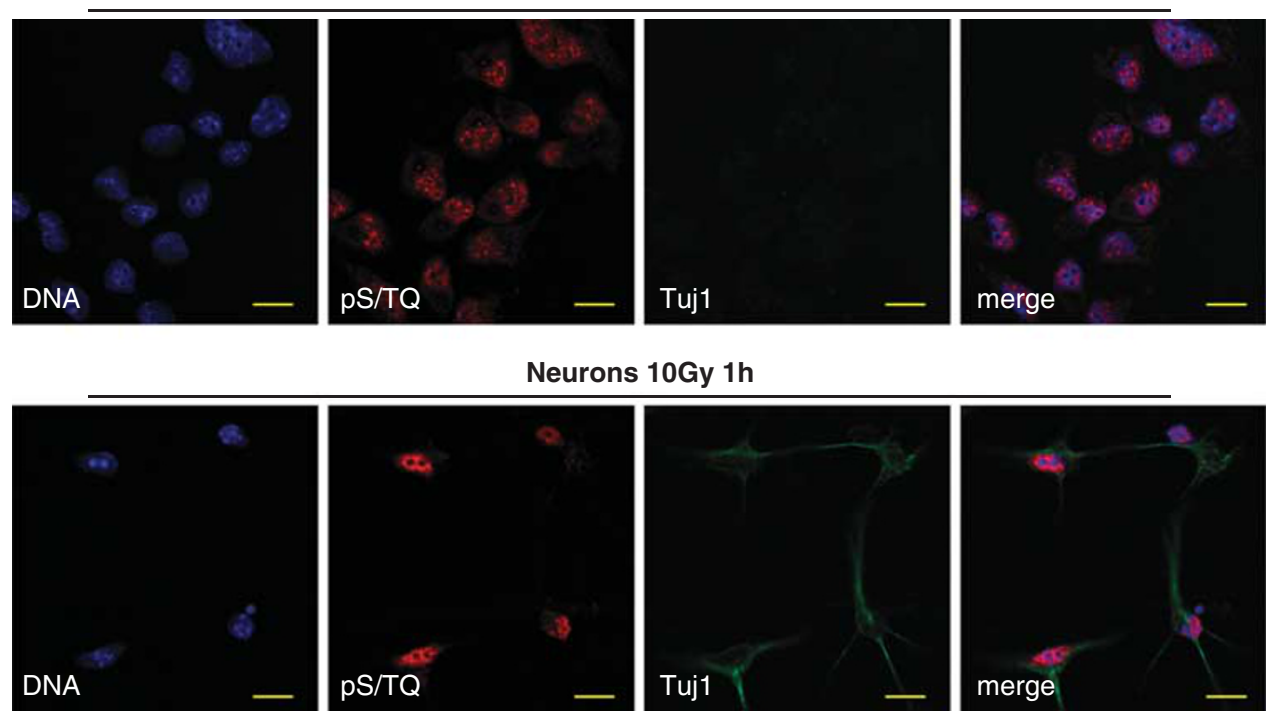

b
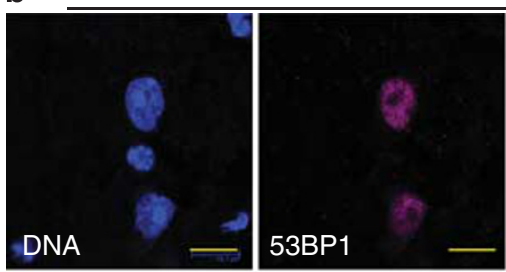

Murine brain, ctrl
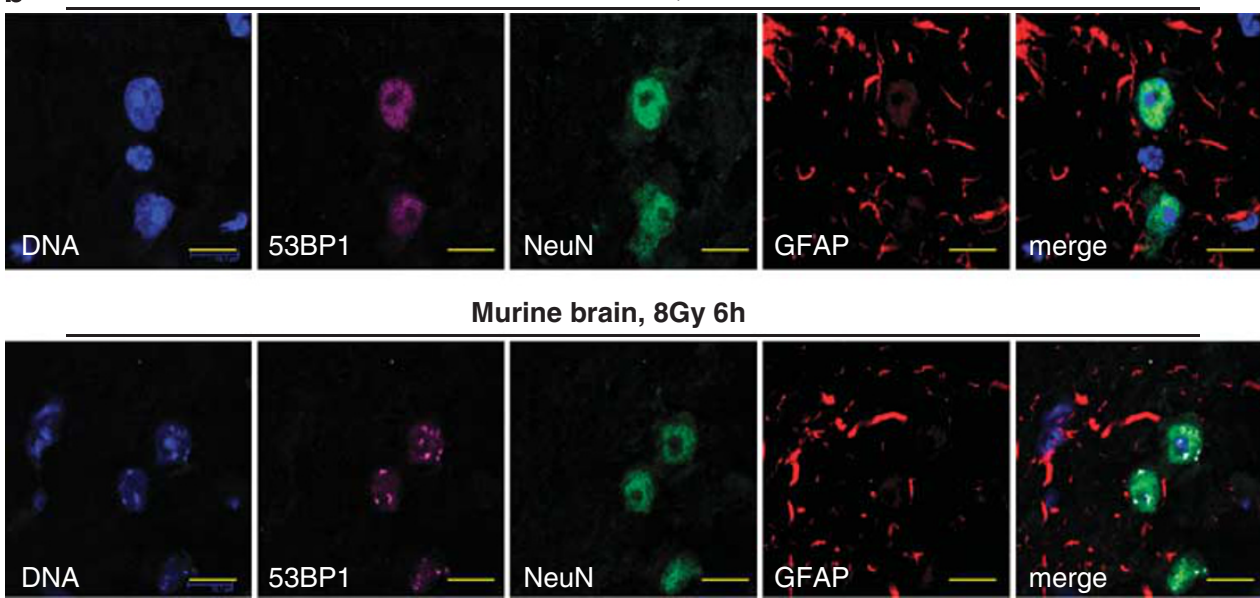

Murine brain, $8 \mathrm{~Gy} 6 \mathrm{~h}$
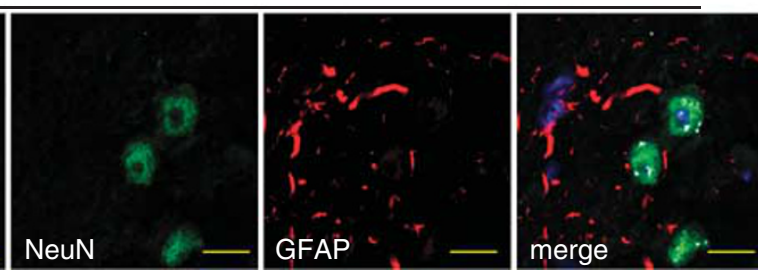

Figure 5 NSC-derived neurons are DDR-proficient. Also in vivo neurons show robust DDR upon irradiation, as opposed to brain astrocytes. (a) Terminally differentiated neurons were derived from NSC according to an established differentiation protocol. ${ }^{21}$ At $1 \mathrm{~h}$ after irradiation with 10 Gy both NSC (here, negative for neuronal marker Tuj1) and NSC-derived neurons (Tuj1 positive) show robust ATM kinase activity through the appearance of foci of phospho-epitope (pS/TQ) as analyzed by confocal immunofluorescence. Bar: $10 \mu \mathrm{m}$. (b) Wild-type mice were untreated or irradiated with a sub-lethal dose of $8 \mathrm{~Gy}$ and killed for brain analysis after $6 \mathrm{~h}$. Neurons were detected using nuclear neuron marker NeuN and astrocytes using intermediate filament GFAP. Activation of DDR was assessed through formation of 53BP1 foci upon irradiation. Neurons show 53BP1 foci assembly $6 \mathrm{~h}$ after 8 Gy delivery, whereas astrocytes do not. Note that astrocytes also lack the diffuse nuclear 53BP1 signal present in neurons. Bar: $10 \mu \mathrm{m}$. Note: GFAP protein in brain astrocytes is known to localize only in their cellular protrusions, hence different signal appearance from GFAP of in vitro astrocytes

non-irradiated cells (Supplementary Figure S9B). At $1 \mathrm{~h}$ after irradiation we detected the formation of prominent $\mathrm{pS} / \mathrm{TQ}$ foci in NSC, which stained negative for Tuj1 (Figure 5a, upper panel). In Tuj1-positive neurons, pS/TQ foci also formed upon irradiation, their intensity being comparable to that in NSC (Figure 5a, lower panel and Supplementary Figure S9B). We conclude that, differently from astrocytes, and consistently with previous reports, ${ }^{22,23}$ neurons do activate canonical DDR upon DNA damage, thus highlighting the unique peculiarity of astrocytes.

Finally, we extended and verified our conclusions in vivo. We irradiated adult mice sub-lethally with $8 \mathrm{~Gy}$ and killed them after $1 \mathrm{~h}$ in order to study DDR activation by immunofluorescence in vivo in their brains (Figure $5 \mathrm{~b}$ ). Analyses of the brain sections by confocal microscopy revealed that neurons, labeled with an antibody against the neuron-specific transcription factor NeuN, showed a diffuse nuclear 53BP1 signal, unlike adjacent GFAP-positive astrocytes (Figure 5b, upper panel). Correspondingly, brain neurons displayed strong 53BP1 foci formation upon irradiation, whereas adjacent astrocytes showed no detectable 53B1 foci (Figure 5b, lower panel), indicating a striking difference of DDR signaling between adjacent neurons and astrocytes in vivo.

\section{Discussion}

We describe here a comparative study of DDR activation and radioresistance in somatic stem cells and their TD descendants. In our system of NSC and NSC-derived astrocytes, we have discovered that NSC show robust 
activation of canonical DDR signaling upon X-ray irradiation, as measured by nuclear foci assembly of activated ATM, its phosphorylation substrates $\mathrm{pS} / \mathrm{TQ}, 53 \mathrm{BP} 1$ and $\gamma \mathrm{H} 2 \mathrm{AX}$, and consistent DDR activation as detected by immunoblotting. This proves that NSC can mount a robust DDR activation upon genotoxic stress and highlights the different regulation of DDR in these somatic stem cells and the embryonic stem cells (from which our NSC derive), which have been reported to show reduced checkpoints and dysfunctional DDR protein localization and functions. ${ }^{24}$

Surprisingly, however, we observed, both in in vitro and in vivo, that the activation of ATM and its downstream DDR factors were strongly inhibited in astrocytes. We show that the mechanism of DDR inhibition involves a stable transcriptional repression of key DDR genes. The astrocytes used in our study are non-proliferating TD cells, thus reproducing the state of the overwhelming majority of adult brain astrocytes. ${ }^{25}$ Deficits in this key feature are the likely reason for a certain degree of DDR activation observed in proliferating astrocytic lines ${ }^{26,27}$ and differentiated astrocytes displaying residual proliferation. ${ }^{28}$ Importantly, downregulation of DDR is peculiar of astrocytes and is not necessarily associated with terminal differentiation. Indeed, as a relevant comparison, we show that neurons display a detectable DDR both in in vitro and in vivo. Similar conclusions in regard to ATM activation in neurons have been reported. ${ }^{22}$

At the current stage, one can speculate if the evolutionary reason for astrocytes to downregulate DDR signaling is to avoid apoptosis upon genotoxic stress. We show that TD astrocytes are, unlike the parental NSC, radioresistant and do not undergo apoptosis upon irradiation. Similar observations were made in TD muscle cells, where the DDR cascade was suppressed at the p53 level. ${ }^{29}$ Irradiation-induced tissue failures may hence derive from the demise of respective stem and progenitor cells, and not TD cells. As we show here, the apoptosis-controlling ATM-CHK2-p53 ${ }^{20}$ axis in astrocytes is strongly attenuated by the transcriptional downregulation of these genes. Indeed, the pro-apoptotic p53-target gene PUMA is hardly induced in irradiated astrocytes, consistent with the observed lack of apoptosis. In NSC, we detected a clear apoptotic response and PUMA was found strongly upregulated, confirming the role of this p53 target in stem cell apoptosis. $^{30}$ In neurons, p53-dependent cell death upon genotoxic stress was also reported, and sometimes associated with their re-entry into cell cycle, ${ }^{31,32}$ whereas in vivo astrocytes are only known to re-enter cell cycle under pathological condition of reactive gliosis. ${ }^{25}$ In this respect in would be interesting to check whether DDR and apoptosis proficiency of brain astrocytes increase when they undergo injury-induced reactive gliosis. It is therefore possible that different TD cell types are differently radiosensitive, depending on their specific role and physiological context.

Despite suppressed DDR signaling pathways, DNA damage induced phosphorylation of H2AX at S139 is still clearly detectable in astrocytes. $\gamma \mathrm{H} 2 \mathrm{AX}$ formation upon DNA damage is commonly associated with ATM function, yet ATM is downregulated and its residual activation is very much delayed compared with the rapid and efficient $\gamma \mathrm{H} 2 \mathrm{AX}$ foci assembly in these cells. ATR expression is inhibited too; this is expected given its specialized role in DNA replication. ${ }^{17}$ The third family member of the DNA-dependent PI3K-like kinases, DNA-PK, is a key enzyme in DSB repair. The DNA-PKdependent NHEJ repair pathway is the main DSB repair pathway used in non-proliferating cells. We found DNA-PK and other key NHEJ genes to be expressed in differentiated astrocytes. Moreover, we revealed that in TD-astrocytes, DNA-PK is actually responsible for DNA-damage-induced H2AX phosphorylation, unlike in NSC, where ATM appears to be the main responsible kinase. Such a substituting role of DNA-PK in cells lacking robust ATM activity is consistent with observations in ATM-deficient cells ${ }^{33-35}$ and mouse models, ${ }^{36,37}$ in which DNA-PK can take over the role of ATM in phosphorylating $\mathrm{H} 2 \mathrm{AX}$. It is worth considering that ATM cannot be directly recruited to $D S B$, rather requiring the DNAbinding role of proteins of the MRE11/RAD50/NBS1 complex, ${ }^{1}$ which we found strongly downregulated in astrocytes. Yet DNA-PK is recruited to broken DNA ends through its KU70/80 subunits. ${ }^{38}$ This binding to DSB would enable the DNA-PK complex to exert its kinase activity on proximal $\mathrm{H} 2 \mathrm{AX}$ despite the transcriptionally suppressed apical DDR signaling cascade in astrocytes.

The disappearance of $\gamma \mathrm{H} 2 \mathrm{AX}$ foci in astrocytes can be interpreted as successful DNA repair and indeed, DSB repair is functional in these cells, as demonstrated by COMET assays. However we observed that in astrocytes inhibition of DNA-PK alone is not sufficient to significantly impair DNA repair in irradiated astrocytes, unless combined with inhibition of ATM. We could indeed detect some amount of delayed ATM activity in irradiated astrocytes. Apparently, these marginal levels of ATM in astrocytes are responsible for DNA repair. This may be a valuable observation when considering ataxia-telangiectasia patients carrying reduced but not completely absent ATM activity or mouse models with hypomorphic ATM alleles.

It remains to be elucidated which mechanisms might be responsible for downregulation of DDR in astrocytes and maybe other TD cells, and for the qualitative differences in DDR proficiency among various types of TD cells. DSB repair kinetics are not equal among cell types ${ }^{39}$ and we have preliminary evidence that in NSC it is faster than in TD astrocytes (data not shown). But also among similar tissues, the efficiency of $\gamma \mathrm{H} 2 \mathrm{AX}$ foci formation and DNA repair vary in age-related manner in TD cells. ${ }^{40}$ Further research also is needed to uncover the physiological and evolutionary reasons on the diversity of DDR, DNA-repair pathways and radioresistance in somatic stem cells and various kinds of TD cells in developing and adult organisms.

\section{Materials and Methods}

Cell culture and treatments. Murine ES-derived NSC ${ }^{13}$ were grown in Euromed-N cell culture medium (Euroclone, Milan, Italy), supplemented with $2 \mathrm{mM}$ L-glutamine, $100 \mathrm{U} / \mathrm{ml}$ penicillin and $100 \mu \mathrm{g} / \mathrm{ml}$ streptomycin, $1 \times \mathrm{N} 2$ supplement (Invitrogen, Carlsbad, CA, USA), $20 \mathrm{ng} / \mathrm{ml}$ murine EGF and FGF2 (ProSpec, Ness-Ziona, Israel) at $5 \% \mathrm{CO} 2$ and $37^{\circ} \mathrm{C}$. Astrocyte differentiation and culture medium was DMEM/F12 with $2 \mathrm{mM}$ L-glutamine, $100 \mathrm{U} / \mathrm{ml}$ penicillin, $100 \mu \mathrm{g} / \mathrm{ml}$ streptomycin and $10 \%$ FCS. Neuron differentiation was performed as described in Spiliotopoulos et al. ${ }^{21}$ NU744 $1^{18}$ and KU55933 ${ }^{19}$ (Tocris, Bristol, UK) were dissolved in DMSO and used at $1 \mu \mathrm{M}$ final concentration overnight before irradiation. X-ray irradiation of cells was performed in a Faxitron RX-650 (Faxitron Bioptics, Lincolnshire, IL, USA) device at $2 \mathrm{~Gy} / \mathrm{min}$ for $5 \mathrm{~min}$ (total of $10 \mathrm{~Gy}$ ) or, where indicated, for $30 \mathrm{sec}$ and $25 \mathrm{~min}$ (total of 1 and $50 \mathrm{~Gy}$, respectively). 
Immunoblotting. Cells were lysed in NP40 lysis buffer $(1 \% \mathrm{NP} 40,50 \mathrm{mM}$ Tris-Cl pH 8, $150 \mathrm{mM} \mathrm{NaCl}, 2 \mathrm{mM}$ EDTA, $1 \mathrm{mM}$ DTT, $1 \mathrm{mM} \mathrm{NaF}, 100 \mu \mathrm{M} \mathrm{Na}_{2} \mathrm{VO}_{4}$ and protease inhibitor cocktail (Roche, Basel, Switzerland)) or or in Lämmli lysis buffer (for $\gamma \mathrm{H} 2 \mathrm{AX}$ analysis) and 20-50 $\mu \mathrm{g}$ of whole cell lysate in Lämmli loading buffer was resolved by SDS-PAGE, transferred to nitrocellulose membranes (Protran, Whatman, Kent, UK) using Biorad (Hercules, CA, USA) electrophoresis systems and probed with primary and secondary antibodies in $5 \%$ bovine serum albumin (BSA) and skimmed milk, respectively.

Antibodies. Mouse monoclonal antibodies against the following were used: Nestin, CHK2, yH2AX (Millipore, Billerica, MA, USA); ATM, vinculin, $\alpha$-tubulin (Sigma Aldrich, St. Louis, MO, USA); ATM pS1981* (Rockland, Gilbertsville, PA, USA); Nestin (BD Biosciences, Franklin Lakes, NJ, USA); Tuj1 (Covance, Princeton, NJ, USA); NeuN (Abcam, Cambridge, UK). Rabbit poly- and monoclonal antibodies against the following were used: GFAP (Dako, Glostrup, Denmark); pS/ TQ, p53 pS15 (Cell Signaling Technology, Danvers, MA, USA); p53 (FL393) (Santa Cruz Biotechnologies, Santa Cruz, CA, USA); 53BP1 (Novus, Littleton, CO, USA); chicken polyclonal antibody against GFAP (Abcam). * $\$ 1981$ of human ATM, against which the antibody was generated, corresponds to Ser1987 of the murine ATM.

Immunofluorescence microscopy. Cells cultured on glass cover slips were fixed in methanol/acetone (1:1,3 min at room temperature), blocked with $0.5 \%$. BSA and $0.2 \%$ gelatin in PBS, and then probed with appropriate primary antibodies and Alexa-fluor 488-, 568- and 647-labeled secondary antibodies (Invitrogen). DNA was counterstained with DAPI (Sigma Aldrich). Confocal images were obtained with a Leica TCS SP2 AOBS confocal laser microscope by sequential scanning.

Gene expression analysis. Total RNA was extracted from live cells with Trizol reagent (Invitrogen), precipitated with isopropanol and ethanol and dissolved in DEPC-treated water (Invitrogen). A volume of $1 \mu \mathrm{g}$ of total RNA (as quantified with NanoVue device, General Electric (GE, Piscataway, NJ, USA)) was used for retrotranscription using VILO reverse transcription kit (Invitrogen) according to manufacturer's instructions and without RNAse treatment. RT-minus reactions (without reverse transcriptase enzyme) were prepared. Estimated $20 \mathrm{ng}$ of cDNA in $25 \mu \mathrm{l}$ reaction volume were analyzed in triplicate by quantitative RT-PCR amplification on a Light Cycler 480 system (Roche) using SYBR Green assay (QuantiFast SYBR Green PCR Kit, Qiagen, Hilden, Germany) according to manufacturer's instructions and for 40 cycles. CT values were obtained by calculation of the second derivative using Light Cycler 480 software (Roche) and normalized among samples against the housekeeping gene (B2M). RT-minus preparations on the housekeeping gene proved to be negative. Forward and reverse primers (FP and RP) were designed with Roche UniversalProbe Library software (Roche) against Mus musculus:

B2M: FP: 5'-CTGCAGAGTTAAGCATGCCAGTA-3'; RP: 5'-TCACATGTCTCGA

TCCCAGTAGA-3'

ATM: FP: 5'-TGCAGATTTATATCCATCATCCAC-3'; RP: 5'-TTTCATGGATTC ATAAGCACCTT- $3^{\prime}$

53BP1: FP: 5'-AAAGTCTGCCACCGTGAAAC-3'; RP: 5'-TCTCCAGTCTCACA GGGACTC- $3^{\prime}$

MRE11: FP: 5'-CTTTTTCAGGCACAGGGAAC-3'; RP: 5'-TGTGATGAGCAT CCCAAAGT-3'

MDC1: FP: 5'-AGGGCAGCTACGTCTCTTCA-3'; RP: 5'-CCAAGGTAGAG GGGGAAATC- $3^{\prime}$

CHK2: FP: 5'-TTATTCCTGAAGTCTGGACAGATG-3'; RP: 5'-CTAACAGT TTCTTGACAAGGTCCA-3'

p53: FP: 5'-ACGCTTCTCCGAAGACTGG-3'; RP: 5'-AGGGAGCTCGAGGCTG ATA-3'

DNA-PKcs: FP: 5'-TGCAGAGAAATGTGATTGCAC-3'; RP: 5'-CCACGGTGGA AGATCTTTTG-3'

KU70: FP: 5'-CAGAACATTCAGGTGACTCCAG-3'; RP: $\quad 5^{\prime}$-GCACCTT CCGCTTGTCAT- $3^{\prime}$

KU80: FP: 5'-GAAGATCACATCAGCATCTCCA-3'; RP: 5'-CAGGATTCACA CTTCCAACCT-3

XRCC4: FP: 5'-TGCATAAATTGCTAAATGAAGTCC-3'; RP: $5^{\prime}$-TTGTCAGAA CACGGATTTTCC- $3^{\prime}$

LIG4: 5': $5^{\prime}$-GAAGAAATCGTGTCCTGATGC-3'; RP: 5'-CAAATCCTCCGGTTT GAACT $-3^{\prime}$
Flow cytometry. For $\gamma \mathrm{H} 2 \mathrm{AX}$ assay, cells were fixed in $75 \%$ ethanol $\left(1 \mathrm{~h}, 4^{\circ} \mathrm{C}\right)$ ), washed with $1 \%$ BSA in PBS and stained with mouse-anti- $\chi \mathrm{H} 2 \mathrm{AX}$ antibody (Millipore), followed by Alexa-fluor-488-labeled secondary antibody (Invitrogen). For TUNEL assay, cells were fixed in $2 \%$ paraformaldehyde $\left(20 \mathrm{~min}\right.$ at $4{ }^{\circ} \mathrm{C}$ ), permeabilized in $75 \%$ ethanol, washed with $1 \%$ BSA in PBS and treated with ' In Situ Cell Death Detection Kit, Fluorescein' (Roche), according to manufacturer's instructions, followed by staining with propidium iodide (Sigma Aldrich). FACS acquisition and analysis were performed on BD FACScalibur using CellQuest software (Becton Dickinson, Franklin Lakes, NJ, USA).

COMET assay. Assay was performed with the CometSlide kit (Trevigen, Gaithersburg, MD, USA) according to manufacturer's instructions for neutral electrophoresis. Between 100 and 200 cells we scored for each experimental condition. COMET tails were analyzed with CometScore 1.5 software, statistical significance of Olive tail moment medians was calculated using Dunn's method for multiple comparisons versus control group.

In vivo DNA-damage assays. Adult mice of C57BL6 strain of 10-12 weeks of age were irradiated with 8 Gy (using a GammaCell 220 device (Nordion, Ottawa $\mathrm{ON}$, Canada) with ${ }^{60} \mathrm{Cobalt}$ as radiation source at about $0.25 \mathrm{~Gy} / \mathrm{s}$ ) and killed $6 \mathrm{~h}$ after irradiation. Brains were cryopreserved in the optimal cutting temperature compound (Tissue-Tek, Torrance, CA, USA). Longitudinal 10 micron thick sections were fixed in $3.7 \%$ formaldehyde, permeabilized with $0.5 \%$ Triton X100, blocked with $5 \%$ goat serum and incubated overnight at $4{ }^{\circ} \mathrm{C}$ with primary antibodies, followed by incubation at room temperature with Alexa-Fluor 488-, 568- or 647labeled secondary antibodies. Cell nuclei were counterstained with DAPI (Sigma Aldrich). Confocal microscopy was performed as above.

\section{Conflict of interest}

The authors declare no conflict of interest.

Acknowledgements. We thank Luciano Conti and Elena Cattaneo for advice, discussions and sharing of protocols and reagents, Thomas Burgold and Giuseppe Testa for help with the establishing of NSC cultures, Barbara Giulini and Alberto Gobbi for help with experimental animal handling, Sara Tomassini for experimental help and all F.d'A.d.F. lab members for discussion and feedback throughou this work. This work was supported by EMBO and DFG (Deutsche Forschungsgesellschaft) fellowships to L.S. F.d'A.d.F's laboratory is supported by AIRC (Associazione Italiana per la Ricerca sul Cancro), Cariplo Foundation (grant number 2010.0818), the European Community's 7th Framework Programme (FP7/ 2007-2013) under grant agreement $n^{\circ}$ 202230, acronym 'GENINCA', HFSP (Human Frontier Science Program) and the EMBO Young Investigator Program.

1. Shiloh Y. The ATM-mediated DNA-damage response: taking shape. Trends Biochem Sci 2006; 31: 402-410.

2. d'Adda di Fagagna F. Living on a break: cellular senescence as a DNA-damage response Nat Rev Cancer 2008; 8: 512-522.

3. Bakkenist CJ, Kastan MB. DNA damage activates ATM through intermolecular autophosphorylation and dimer dissociation. Nature 2003; 421: 499-506.

4. Burma S, Chen BP, Murphy M, Kurimasa A, Chen DJ. ATM phosphorylates histone H2AX in response to DNA double-strand breaks. J Biol Chem 2001; 276: 42462-42467.

5. Schultz LB, Chehab NH, Malikzay A, Halazonetis TD. P53 binding protein 1 (53bp1) is an early participant in the cellular response to DNA double-strand breaks. J Cell Biol 2000; 151: $1381-1390$.

6. Jowsey P, Morrice NA, Hastie CJ, McLauchlan H, Toth R, Rouse J. Characterisation of the sites of DNA damage-induced 53BP1 phosphorylation catalysed by ATM and ATR. DNA Repair 2007; 6: 1536-1544.

7. Khanna KK, Jackson SP. DNA double-strand breaks: signaling, repair and the cancer connection. Nat Genetics 2001; 27: 247-254.

8. Mahaney BL, Meek K, Lees-miller SP. Repair of ionizing radiation-induced DNA double-strand breaks by non-homologous end-joining. Biochem J 2009; 417: 639-650.

9. Freeman MR. Specification and morphogenesis of astrocytes. Science 2010; 330: 774-778.

10. Doetsch F. The glial identity of neural stem cells. Nat Neurosci 2003; 6: 1127-1134.

11. Schull WJ. Brain damage among individuals exposed prenatally to ionizing radiation: a 1993 review. Stem Cells 1997; 15: 129-133.

12. Kal HB, Struikmans $H$. Radiotherapy during pregnancy: fact and fiction. Lancet Oncol 2005; 6: 328-333.

13. Conti L, Pollard SM, Gorba T, Reitano E, Toselli M, Biella G et al. Niche-independent symmetrical self-renewal of a mammalian tissue stem cell. PLoS biol 2005; 3: e283. 
14. Noon AT, Shibata A, Rief N, Lobrich M, Stewart GS, Jeggo PA et al. 53BP1-dependent robust localized KAP-1 phosphorylation is essential for heterochromatic DNA doublestrand break repair. Nat Cell Biol 2010; 12: 177-184.

15. Canman CE, Lim D-S, Cimprich KA, Taya Y, Tamai K, Sakaguchi K et al. Activation of the ATM kinase by ionizing radiation and phosphorylation of p53. Science 1998; 281: 1677-1679.

16. Roos WP, Kaina B. DNA damage-induced cell death by apoptosis. Trends Mol Med 2006; 12: $440-450$.

17. Kinner A, Wu W, Staudt C, lliakis G. H2AX in recognition and signaling of DNA doublestrand breaks in the context of chromatin. Nucleic Acids Res 2008; 36: 5678-5694.

18. Leahy JJJ, Golding BT, Griffin RJ, Hardcastle IR, Richardson C, Rigoreau L et al. Identification of a highly potent and selective DNA-dependent protein kinase (DNA-PK) inhibitor (NU7441) by screening of chromenone libraries. Bioorg Med Chem Lett 2004; 14 6083-6087.

19. Hickson I, Zhao Y, Richardson CJ, Green SJ, Martin NMB, Orr Al et al. Identification and characterization of a novel and specific inhibitor of the ataxia-telangiectasia mutated kinase ATM. Cancer Res 2004; 64: 9152-9159.

20. Olive PL. Impact of the comet assay in radiobiology. Mutat Res/Rev Mutat Res 2007; 681: 13-23.

21. Spiliotopoulos D, Goffredo D, Conti L, Di Febo F, Biella G, Toselli M et al. An optimized experimental strategy for efficient conversion of embryonic stem (ES)-derived mouse neural stem (NS) cells into a nearly homogeneous mature neuronal population. Neurobiol Disease 2009; 34: 320-331.

22. Biton S, Gropp M, Itsykson P, Pereg Y, Mittelman L, Johe K et al. ATM-mediated response to DNA double strand breaks in human neurons derived from stem cells. DNA Repair 2007; 6: $128-134$

23. Gorodetsky E, Calkins S, Ahn J, Brooks PJ. ATM, the Mre11/Rad50/Nbs1 complex, and topoisomerase I are concentrated in the nucleus of Purkinje neurons in the juvenile human brain. DNA Repair 2007; 6: 1698-1707.

24. Hong Y, Cervantes RB, Tichy E, Tischfield JA, Stambrook PJ. Protecting genomic integrity in somatic cells and embryonic stem cells. Mutat Res 2007; 614: 48-55.

25. Buffo $A$, Rolando $C$, Ceruti S. Astrocytes in the damaged brain: molecular and cellular insights into their reactive response and healing potential. Biochem Pharmacol 2010; 79: 77-89.

26. Bartkova J, Hamerlik P, Stockhausen MT, Ehrmann J, Hlobilkova A, Laursen $\mathrm{H}$ et al. Replication stress and oxidative damage contribute to aberrant constitutive activation of DNA damage signalling in human gliomas. Oncogene 2010; 29: 5095-5102.

27. Burdak-Rothkamm S, Short SC, Folkard M, Rothkamm K, Prise KM. ATR-dependent radiation-induced gamma $\mathrm{H} 2 \mathrm{AX}$ foci in bystander primary human astrocytes and glioma cells. Oncogene 2006; 26: 993-1002.
28. Adams BR, Golding SE, Rao RR, Valerie K. Dynamic dependence on ATR and ATM for double-strand break repair in human embryonic stem cells and neural descendants. PLOS ONE 2010; 5: e10001.

29. Latella L, Lukas J, Simone C, Puri PL, Bartek J. Differentiation-induced radioresistance in muscle cells. Mol Cell Biol 2004; 24: 6350-6361.

30. Akhtar RS, Geng Y, Klocke BJ, Latham CB, Villunger A, Michalak EM et al. BH3-only proapoptotic $\mathrm{Bcl}-2$ family members noxa and puma mediate neural precursor cell death. J Neurosci 2006; 26: 7257-7264

31. Morrison RS, Kinoshita Y, Johnson MD, Guo W, Garden GA. p53-dependent cell death signaling in neurons. Neurochem Res 2003; 28: 15-27.

32. Barzilai A, Biton S, Shiloh Y. The role of the DNA damage response in neuronal development, organization and maintenance. DNA Repair 2008; 7: 1010-1027.

33. Takahashi A, Mori E, Su X, Nakagawa Y, Okamoto N, Uemura $\mathrm{H}$ et al. ATM is the predominant kinase involved in the phosphorylation of histone $\mathrm{H} 2 \mathrm{AX}$ after heating. J Radiat Res 2010; 51: 417-422

34. Stiff T, O'Driscoll M, Rief N, Iwabuchi K, Löbrich M, Jeggo PA. ATM and DNA-PK function redundantly to phosphorylate $\mathrm{H} 2 \mathrm{AX}$ after exposure to lonizing radiation. Cancer Res 2004; 64: $2390-2396$.

35. Reitsema T, Klokov D, Banáth JP, Olive PL. DNA-PK is responsible for enhanced phosphorylation of histone H2AX under hypertonic conditions. DNA Repair 2005; 4: $1172-1181$

36. Koike M, Sugasawa J, Yasuda M, Koike A. Tissue-specific DNA-PK-dependent H2AX phosphorylation and gamma-H2AX elimination after X-irradiation in vivo. Biochem Biophys Res Commun 2008; 376: 52-55.

37. Bellani MA, Romanienko PJ, Cairatti DA, Camerini-Otero RD. SP011 is required for sexbody formation, and Spo11 heterozygosity rescues the prophase arrest of Atm-/spermatocytes. J Cell Sci 2005; 118: 3233-3245.

38. Yano K-i, Morotomi-Yano K, Adachi N, Akiyama H. Molecular mechanism of protein assembly on DNA double-strand breaks in the non-homologous end-joining pathway. J Radiat Res 2009; 50: 97-108.

39. Hande MP, Natarajan AT. Induction and Persistence of Cytogenetic Damage in Mouse Splenocytes Following Whole-Body X-Irradiation Analysed by Fluorescence In Situ Hybridisation. V. Heterogeneity/Chromosome Specificity In: Nakashima M, Takamura N, Tsukasaki K, Nagayama Y, Yamashita S (eds). Radiation Health Risk Sciences. Springer: Japan, 2009 pp 143-149.

40. Hudson D, Kovalchuk I, Koturbash I, Kolb B, Martin OA, Kovalchuk O. Induction and persistence of radiation-induced DNA damage is more pronounced in young animals than in old animals. Aging (Albany NY) 2011; 3: 609-620.

\section{Supplementary Information accompanies the paper on Cell Death and Differentiation website (http://www.nature.com/cdd)}

